\title{
Sleep Apnea: A Brain Disease?
}

\author{
Neil S. Cherniack \\ New Jersey Medical School, University of Medicine and Dentistry of New Jersey, \\ Newark, N.J., USA
}

Research in both obesity and sleep has blossomed in the past decade. The close association between obesity and the obstructive sleep apnea syndrome has led to the idea that weight and sleep have common regulatory elements.

Leptin, interleukin- 6 and tumor necrosis factor- $\alpha$ are all increased in the plasma of middle-aged men with obstructive sleep apnea [1]. One idea is that their increased levels are related to visceral fat accumulation and mediate daytime sleepiness. They are believed to contribute to the metabolic syndrome, which includes sleep apnea combined with arteriosclerosis, diabetes and hypertension. Leptin produced mainly by the ob gene in adipocytes crosses into the brain to stimulate appetite suppressants like melanocortin produced by neurons in the hypothalamus (pro-opiomelanocortin and cocaine-amphetamine-regulated transcript neurons) and suppress formation of appetite-stimulating substances like neuropeptide Y (NPY) and the Agouti-related peptide [2]. In addition, leptin affects the body more generally by modifying bone mass and glucose metabolism via transmembrane receptors that are structurally similar to cytokine receptors [3].

Orexins (also known as hypocretins) are another type of neuropeptide that increase appetite. They are produced by a relatively small group of neurons in the lateral hypothalamus that send projections widely in the nervous system [4]. There are two types, A and B, which act on at least two differing kinds of receptors. Orexin-containing neurons project to NPY neurons and some of their effects may be due to NPY stimulation. It is not clear whether orexin synthesis is suppressed by leptins.

Patients with narcolepsy have been reported to have low cerebrospinal fluid levels of orexin suggesting that the peptide is involved in maintaining alertness [4]. Animals with mutated genes for orexin or orexin receptors develop a narcolepsy-like syndrome and experience fragmented sleep.

In this issue of Respiration, Busquets et al. [5] report low plasma levels of orexin in patients with the obstructive sleep apnea syndrome compared to normal controls. In untreated patients, orexin levels were not related to body size or daytime sleepiness. They suggest that the low orexin level produces a background of decreased alertness, which could play a role in the etiology of obstructive sleep apnea.

This is a quite intriguing idea. Sleep apnea might be a kind of neurological disease in which diminished alertness plays a role, but there are other explanations for low orexin levels. In obesity, leptin levels tend to be high and orexin levels low. However, low orexin levels were also observed in non-obese patients.

Although leptin levels have not been measured in the study by Busquets et al., they have been reported to decrease with continuous positive airway pressure even after only 3-4 nights of treatment, which raises the possi-

\begin{tabular}{ll}
\hline KARGER & ( ) 2004 S. Karger AG, Basel \\
Fax +41 61306 1234 & 0025-7931/04/0716-0553\$21.00/0 \\
$\begin{array}{l}\text { E-Mail karger@karger.ch } \\
\text { www.karger.com }\end{array}$ & $\begin{array}{l}\text { Accessible online at: } \\
\text { www.karger.com/res }\end{array}$
\end{tabular}

Neil S. Cherniack, Professor of Medicine and Physiology

Department of Medicine, UMDNJ-New Jersey Medical School

185 South Orange Avenue

Newark, NJ 07103-2714 (USA)

Tel.+1973972 7937, Fax +1973972 7104,E-Mail cherniac@umdnj.edu 
bility that sleep apnea causes an increase in leptin levels rather than the other way around [6]. It has been reported that intermittent hypoxia, which occurs for example in untreated sleep apnea, raises leptin levels through a process involving hypoxia-inducible factor (HIF) [7]. In addition, the enhanced sympathetic activity that occurs with sleep interruption may increase leptin levels [8]. However, in the present study, treated as well as untreated patients had low orexin levels, but the same patients were not studied before and after treatment.

Controversy exists regarding the role of alertness in sleep apnea. It is certainly better for sleep apneics to be more alert during the day, but Busquets et al. [5] found no relationship between orexin levels and daytime sleepiness.
During the night, easy arousability is believed to terminate sleep apneas. Indeed, a recent paper reported high orexin A levels in sleep apneics, assuming a compensatory change which facilitated a shortened apnea length [9]. Younes et al. could not find a good relationship between arousal occurrence and the termination of apneic episodes during sleep [10]. Moreover, the increased sympathetic activity that occurs with arousals has been cited as an etiological factor in the development of hypertension [8].

So is the obstructive sleep apnea syndrome a disease of the brain rather than a condition arising from a local abnormality in upper air way mechanics? It may be that we need more data.

\section{References}

$>1$ Vgontzas AN, Panicolaou DA, Bixler EO, Hopper K, Lotsikas A, Lin HM, Kales A, Chrousos GP: Sleep apnea and daytime sleepiness and fatigue; relation to visceral obesity, insulin resistance, and hypercytokinemia. J Clin Endocrinol Metab 2000;85:1151-1158.

$\checkmark 2$ Harvey J, Ashford MLJ: Leptin in the CNS Much more than a satiety signal. Neuropharmacology 2003;44:843-854.

$\checkmark 3$ Cock TA, Auwerx J: Leptin: Cutting the fat off the bone. Lancet 2003;362:1572-1574.

$\checkmark 4$ Sakurai T: Role of orexins in the regulation of feeding and arousal. Sleep Med 2002;3:S3-S9.
$>5$ Busquets X, Barbé F, Barceló A, de la Peña M, Sigritz N, Mayoralas LR, Ladaria A, Agustí A: Decreased plasma levels of orexin-A in sleep apnea. Respiration 2004;71:575-579.

$\checkmark 6$ Chin K, Shimizu K, Nakamura T, Narai N, Masuzaki H, Ogawa Y, Mishima M, Nakamura T, Nakao K, Ohi M: Changes in abdominal visceral fat and serum leptin levels in patients with obstructive sleep apnea syndrome following nasal continuous positive airway pressure therapy. Circulation 1999;100:706-712.

$>7$ Ambrosini G, Nath AK, Sierra-Honigmann MR, Flores-Riveros J: Transcriptional activation of the human leptin gene in response to hypoxia. Involvement of hypoxia-pinducible factor 1. J Biol Chem 2002;277:34601-34609.
8 Snitker S, Prately RE, Nicholson M, Tararanni PA, Ravussin E: Relationship between muscle sympathetic nerve activity and plasma leptin concentration. Obes Res 1997;5:338-340.

-9 Igarashi N, Tatsumi K, Nakamura A, Sakao S, Takiguchi Y, Nishikawa T, Kuriyama T: Plasma orexin-A levels in obstructive sleep apneahypopnea syndrome. Chest 2003;124:13811385.

10 Younes M: Role of arousals in the pathogenesis of obstructive sleep apnea. Am J Crit Care Med 2004;169:623-633. 